\title{
RIO BRANCO E A SUA POLÍTICA EXTERNA.
}

São pràticamente inexistentes as declarações sôbre política externa deixadas pelo Barão do Rio Branco. Embora haja uma imensa bibliografia referente à sua carreira de Ministro de Relações Exteriores e os arquivos estejam repletos de material sôbre o assunto, mesmo as mais cuidadosas buscas serão infrutíferas para encontrar um programa formal e sistematizado, que tenha servido de guia à política externa do Brasil durante os nove anos e dois meses do mandato de Rio Branco. Devido às vantagens da perspectiva histórica, podese òbviamente reconstruir seus atos $e$, dêste modo, deduzir sua política externa. Essa maneira artificial de reconstrução é perfeita. Tende, porém, a ofuscar a realidade do fato de Rio Branco nunca ter publicado oficialmente o programa de sua política externa para o Brasil. O estadista brasileiro parecia contentar-se em permitir que suas ações no âmbito da política externa falassem por êle. Alvaro Lins, em sua excelente biografia de Rio Branco, assim se expressou sôbre êsse fato:

"Poucos também lhe conheciam o pensamento nos negócios públicos antes que o exprimisse em ação" (1).

Apesar da escassez de declarações sôbre política externa, Rio Branco teve, òbviamente, idéias definidas sôbre as relações diplomáticas do Brasil, pondo-as em prática durante o seu mandato. Um de seus objetivos na política externa foi o de fixar os limites extensos e ainda mal definidos do Brasil. Suas vitórias nas controvérsias sôbre a posse do Território das Missões em 1895 e do Amapá em 1900, ambas submetidas a juízo arbitral, foram o início de uma série notável de intervenções diplomáticas, que terminaram com o tratado com o Uruguai, em 1909. Rio Branco prosseguiu com uma política de franca cooperação e amizade com os Estados Unidos, salientada pela

(1). - Rio Branco (Rio, 1945), II, pp. 470-471. 
elevação das legações em Washington e Rio de Janeiro à categoria de embaixadas, em 1905, e pela visita do Secretário de Estado, Elihu Root, ao Rio de Janeiro, em 1906. Obtendo para - Brasil o primeiro cardinalato latino-americano, expandindo a representação do Brasil no estrangeiro, assinando trinta e um tratados de arbitramento, defendendo os direitos das pequenas nações em Haia, sendo o anfitrião do vitorioso Terceiro Congresso Pan-Americano, etc., Rio Branco conseguiu restabelecer o prestígio do Brasil no estrangeiro e transformá-lo na primeira nação sul-americana: $E$ apesar de verbalmente indefinida, sua política externa alcançou um brilhante êxito.

Meio século mais tarde, os objetivos de sua política externa parecem óbvios. Não porque o Ministro do Exterior os tenha codificado e publicado, mas porque, durante aquêle período, a atitude do Brasil, em face a essa política, os revela. Estes objetivos foram aceitos pelos estudiosos do assunto, uma vez que o estabelecimento definitivo de fronteiras, a aproximação com os Estados Unidos, o engrandecimento e o aumento de prestígio internacional eram o conjunto que formava uma política de visão ampla e fàcilmente apreendida. Todavia, dentre êsses esboços de uma ampla política externa, havia outros objetivos de Rio Branco que eram menos discrimináveis, talvez devido à sua maior sutileza. Os estudiosos desprezaram, negligenciaram e mesmo divergiram dêsses objetivos menores e menos óbvios.

Uma das razões em se hesitar numa classificação definitiva da política externa de Rio Branco é o total desconhecimento de seus escritos. Os numerosos despachos, ordens e telegramas que êle enviava aos chefes das missões diplomáticas, por exemplo, permanecem de certa forma negligenciados pelos pesquisadores, no rico Arquivo Histórico do Itamaratí. Sòmente quando todos êsses documentos forem reunidos e publicados, será possível ao pesquisador estabelecer as aspirações e objetivos do grande chanceler com mais acêrto. Até que esta tarefa monumental esteja concluída, novos documentos aperecerão ocasionalmente, acrescentando um detalhe ou outro à história do ministério de Rio Branco e à sua política externa.

O presente ensaio refere-se apenas a um dêsses documentos. Quando pesquisava os Arquivos Nacionais dos Estados Unidos da América, minha atenção foi atraída por uma breve carta do Embaixador brasileiro Joaquim Nabuco ao Secretário 
tde Estado Elihu Root, amigo entusiasta do Brasil. O Embaixador Nabuco comentava um artigo do Jornal do Comércio, que lhe fôra enviado por Rio Branco. Nabuco, observando

"ter o artigo sido escrito de acôrdo com os pontos de vista de nosso Ministro do Exterior" (2),

remetera-o ao Secretário de Estado. Ao mesmo tempo, telegrafava ao Barão do Rio Branco, exprimindo sua aprovação pelo "excelente" artigo (3). O Embaixador ficara indubitàvelmente encantado, considerando-o uma declaração evidente de política externa.

$\mathrm{O}$ artigo foi disfarçadamente intitulado "O Congresso PanAmericano" e ficou muito tempo em evidência. Chegou mesmo a despertar a atenção de três dos maiores estadistas do hemisfério, mas foi pouco depois pôsto de lado, permanecendo esquecido na segunda página da edição do Jornal do Comércio de 11 de dezembro de 1905 . Jamais vi qualquer referência a êsse artigo; tampouco encontrei qualquer citação dêle tirada, nos inúmeros livros e ensaios que li sôbre Rio Branco. Essa falta de divulgação torna-se completamente desmerecida, quando consideramos o significado que Nabuco deu ao artigo. Além disso, essa negligência é extremamente prejudicial, uma vez que "O Congresso Pan-Americano" contém uma série de declarações de grande importância para a compreensão da política externa de Rio Branco.

Sendo êste artigo muito pouco conhecido, será transcrito abaixo, a fim de divulgá-lo mais amplamente, torná-lo mais acessível e servir de base para a exposição que se lhe segue.

\section{O CONGRESSO PAN-AMERICANO.}

A última reunião do Congresso Pan-Americano foi em 1901, no México. Nestes cinco anos os grandes fatos internacionais têm sido tão vários e graves que nas idéias politicas do nosso continente se nota uma remodelação súbita, nascida de um vivo sentimento da universalidade do seu destino, que vai inspirando e engrandecendo a consciência dos povos americanos.

Nesta importante variação de princípios, de que os acréscimos feitos à doutrina de Monroe pelo Presidente Roosevelt já nos dão uma impressão, é que está seguramente $o$ interêsse da próxima conferência do Rio de Janeiro.

(2). - Arquivos Nacionais dos EUA, Joaquim Nabuco a E. Root, 8 de janeiro de 1906, Notas da Legação Brasileira, volume 8.

\{3). - Arquivo Histórico do Itamaratí, Nabuco a Rio Branco, 6 de janeiro de 1906, Washington, Telegramas Recebidos, 235-3-1A. 
A nossa época tem assistido aos mais ilusórios Congressos, e o direito de zombar de declarações de princípios em conferências internacionais é uma conquista. de uma experiência de decepções inflingida à inextiguível candura do espírito humano... Ainda assim, neste jôgo. perpètuamente falaz de utopistas e práticos, é sempre be-. néfico o encontro de homens, o convívio ainda instantânea. de representantes e transmissores de culturasè diferentes. E' mais um aspecto dessa sociabilidade invencivel e fecun-. da, que é o motivo profundo da civilização.

E' provável, no entanto, que o Congresso Pan-Ame-ricano não trace vaga e fugitiva a sua passagem. Com a. intensa necessidade que têm os países americanos de assegurar a sua existência internacional, vai-se consolidando um ideal coletivo de um continente que quer participar com a Europa dos mesmos princípios, em que esta funda a organização politica dos seus povos. Deve-se. esperar que as declarações do Congresso exprimam perfeitamente as intimas aspirações das nações americanas. Por isso, do fato de se reunir uma conferência americana não se deve concluir que a América lance um desafio à Europa, e que seu sentimento coletivo seja hostils ao progresso e ao ideal europeu. $O$ que a América deseja é a igualdade no direito internacional, que até aqui. tem gozado, e que a soberania de suas nações seja acatada como a das naçōes européias. $O$ que a América repele é tôda a tentativa de aplicação dos chamados princípios africanos a qualquer porção de seu continente livre. O território será intangível à cobiça e à conquista. européia. A América só deseja ser conquistada pacìficamente por essa cultura, que é a glória da Europa, a. dignidade do espírito humano. Absorvendo com as fôrças assombrosas do nosso mundo físico as energias das: raças brancas, nós aspiramos a atrair para esta margem: do oceano a onda luminosa do gênio europeu. Mas, ou-tra forma violenta de preponderância, qualquer que se-. ja, os americanos repeli-la-ão tenazmente com a vibração de um sentimento que, sejam quais forem as diferenças nacionais de cada país, se manifestará vivaz e. enérgico, como a descarga elétrica de uma atmosfera. comum. Não se proclamará na Conferência, estamos certos, um direito americano diferente do direito europeu; $o$. que há e haverá é o mesmo direito de uma civilização que. procura envolver todos os povos, sem diferenças de clima, nem de raças.

Em relação à América o grande serviço prestado pelar doutrina de Monroe é o da liberdade assegurada ao desen-. volvimento das fôrças de cada nação americana. 
Sem temor de violências externas e injustificáveis, nem provocadas pela selvageria e pela corrupção, cada povo americano pode atingir o máximo da cultura à sombra dessa doutrina, que teve na história das idéias politicas um destino tão singular e surpreendente. Raras vêzes se viu um simples princípio doutrinário transmudar o curso de outras correntes reputadas mais naturais; e à expansão dos povos fortes, à eliminação dos fracos, à ocupação das regiões desabitadas - teoria dominante depois das descobertas do século XVI - sucedeu na América, pelo menos, o principio do respeito à independência e soberania de tôdas as nações, princípio que a Inglaterra adotou desde Canning e só veio a repudiar na guerra ao Transvaal. Mas a América do Sul nada pode recear com a transformação da política inglêsa, porque a doutrina de Monroe não é uma abstração; tem a sua base principal na prodigiosa ascendência dos Estados Unidos.

A América Latina nada tem a temer da América anglo-saxônica. Os Estados Unidos são uma nação de origem e princípios inglêses e, portanto, fecundos para a civilização dos outros povos, porque o sentimento do individualismo é tão entranhado na raça que o imperialismo inglês ou americano do norte, se êste se manifestasse, jamais seria do molde do imperialismo latino ou germânico, que tudo devasta e aniquila, tudo contorce, para fabricar com as incompatibilidades as mais inconciliáveis, um mesmo tipo de Estado em tôdas as regiões do mundo. E nada, absolutamente nada, na política dos Estados Unidos poderia trazer uma inquietação à sensibilidade nacional dos outros países americanos. Longe disto, êstes só têm encontrado na preponderância da primeira nação do contịnente apôio para as suas causas e aspirações.

Se uma vez, algum país se mostrou descontente com a República Americana, foi quando o Presidente Roosevelt proclamou que a doutrina de Monroe não podia servir de bandeira à política de falências e de pirataria internacional.

O Brasil, que é solidário com esta interpretação honesta de monroísmo, orgulha-se com a simpatia espontânea e decidida da nação americana e do seu grande Presidente. Não há amizade mais cobiçada no mundo. A Inglaterra proclama esta amizade como inquebrantável e, para não rompê-la, submeteu-se à Mensagem Cleveland, considerada como ultimatum, em que os Estados Unidos reclamavam o arbitramento para a questão entre a Guiana Inglêsa e a Venezuela; o Imperador da Alemanha, cuja sagacidade e poder todo o mundo re- 
conhece, mandou visitar a República Americana por seu irmão, o Príncipe Henrique da Prússia, e a um couraçado alemão, construído nos estaleiros americanos, serviu de madrinha Miss Alice Roosevelt; a França, a Rússia, o Japão, sejam quais forem os seus sistemas de aliança, aspiram contar com a simpatia dos Estados Unidos, como um fator de importância capital. A paz de Portsmouth foi o ponto culminante dêsse prestígio maravilhoso.

Na história diplomática brasileira não há traço de qualquer ocorrência, como sempre acontece na vida internacional, que possa por uma impressão persistente enfraquecer a nossa amizade com os Estados Unidos. Durante o Império, os três incidentes desagradáveis de Condy Raguet, no primeiro reinado, de Whise e Webb no segundo, foram resolvidos com honra para o Brasil, sem intervenção de qualquer outro país, pelo Govêrno Americano, que desaprovou e puniu os seus agentes. E o Imperador, que não tinha motivos para guardar ressentimentos de tais incidentes, foi em 1876 aos Estados Unidos e voltou dali cheio de assômbro e de estímulo. $\mathrm{Na}$ República, a nossa aproximação com a América do Norte era fatal.

Para prova de quanto a simpatia dos Estados Unidos nos tem serviço, basta referir que o arbitramento na questão de Oyapoc foi devido em grande parte à certeza havida em Paris de que o Brasil não estaria isolado no caso de uma nova tentativa de ocupação militar. Nessa época tinham decorrido apenas alguns meses depois do ultimatum Cleveland.

A pressurosa reciprocidade com que o Govêrno Americano elevou a dignidade da sua representação no Rio de Janeiro e a iniciativa que tomou na escôlha desta capital para a reunião do próximo Congresso Pan-Americano, são significativas demonstrações de uma boa e confortante amizade.

Se as razões políticas já não fôssem suficientes para dar uma importância real à conferência do Rio de Janeiro, a presença em nosso país do Ministro das Relações Exteriores dos Estados Unidos, o Sr. E. Root, é assaz expressiva para ser considerada um acontecimento da primeira ordem na atualidade. Não é um delegado; é um membro do próprio Govêrno Americano que, pela primeira vez na sua história política, visita outra nação. Coube ao Brasil esta honrosa distinção, conquistada naturalmente pela segurança que a República Norte-Americana tem de nossa lealdade e da nossa intima simpatia. 
Em companhia do Ministro americano, vem ao Brasil o Sr. Joaquim Nabuco, o nosso embaixador em Washington.

Depois de umá ausência de sete longos anos, em que só tem enobrecido o nome brasileiro, não podia o eminente diplomata de modo mais significativo e mais brilhante voltar a essa terra, que se orgulha de o ter como filho.

O Ministro Root vem do país mágico que é a sua pátria. Os seus olhos não se poderão deslumbrar diante das nossas incipientes conquistas materiais; mas a sua filosofia de americano e de forte se alegrará quando notar que há um fenômeno nôvo na raça brasileira - a atividade, a energia e a esperança.

Transfomrando pela ciência e pela indústria o nosso país, queremos assegurar-lhe um lugar proeminente entre as nações americanas. O nosso dever coletivo é corresponder com firmeza a êsse ideal de uma região feliz, que do Brasil fazem as raças emigrantes, desejosas de paz e trabalho. E' preciso que em face dêsse problema industrial e científico não sejamos atingidos por nenhum dos males políticos que principalmente prejudicaram os povos sul-americanos. Não há nada mais ridículo e extravagante do que as manifestações de caudilhismo, os pronunciamentos, as revoluções para a posse do poder, a demagogia militar. Aos estrangeiros, que vêm honrar-nos e seguramente pasmarão da mudança do nosso temperamento, não nos contentamos de dar a deliciosa e enganadora miragem de uma ilusão brasileira.

A brilhante política internacional, em que resolutamente entrou o Brasil, será um fator de progresso interno. O respeito e a simpatia que nos chegam das outras nações aumentarão a nossa responsabilidade e nos darão maior consciência do nosso destino. Não duvidamos por isso em concluir que esta maior aproximação do grande povo americano foi o maior serviço que à causa da civilização brasileira prestou o Sr. Barão do Rio Branco. E à coroação de sua obra política. As vitórias que nos alcançou na defesa do território nacional, e o aumento considerável que pelos seus estudos ou pelo seu tato ou pelos seus sentimentos pacíficos trouxe ao território brasileiro foram serviços extraordinários. Mas a sua glória de estadista está neste despertar miraculoso do Brasil, dando-lhe o relêvo internacional que jamais teve desde os seus princípios de nação. Depois de uma experiência de três anos, o país pode formar sôbre o atual Ministro das Relações Exteriores um juízo definitivo, e quem estudar atentamente a obra feita, concluirá que naquele ramo da administração pública ainda não esteve um ho- 
mem que o excedesse pelo conhecimento da nossa história diplomática, pelo engenho das soluçóes em negócios considerados insolúveis, pelo fogo sagrado na defesa do direito e do prestígio brasileiro.

(Jornal do Comércio, 11 de dezembro de 1905. Página 2, Ano 85, N. ${ }^{\circ} 544$ ).

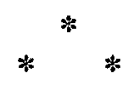

O artigo não foi assinado. Com isso, surgiu a possibilidade de ter sido escrito pelo próprio Rio Branco, surgindo também a pergunta: que motivos nos levariam a acreditar em tal possibilidade? No Arquivo Histórico do Itamaratí e nos Arquivos Nacionais dos Estados Unidos, a evidência aponta o singular interêsse de Rio Branco pelo artigo. Rio Branco remeteu a Nabuco uma cópia, logo após sua publicação. Por sua vez, Nabuco, felicitando o Barão, enviou o recorte a Root. Ésse tratamento especial não seria dado a um simples artigo do Jornal do Comércio. Aparentemente, havia algo de extraordinário relacionado com "O Congresso Pan-Americano". E o que havia de extraordinário em sua aparência estava em seu conteúdo e em sua fonte de informações.

Uma análise mais pormenorizadá de seu conteúdo, sua fraseologia, seu estilo, e da ênfase empregada nos leva à indicação de Rio Branco como o autor da maior parte ou mesmo de todo o artigo. Em "O Congresso Pan-Americano", são encontradas várias declarações semelhantes em pensamento ou em escôlha de palavras a frases ou idéias, autêntica e reconhecidamente de Rio Branco. A melhor maneira de provar essa semelhança é selecionar ao acaso uma meia dúzia de exemplos tirados do artigo e compará-los a declarações conhecidas de Rio Branco. A semelhança entre as duas séries de declarações abaixo transcritas, a da esquerda tirada de "O Congresso Pan-Americano" e a da direita dos escritos de Rio Branco, leva-nos a acreditar que o artigo anônimo tenha sido escrito pelo Ministro do Exterior.

Como primeiro exemplo, nêle encontramos o ponto de vista freqüentemente expresso por Rio Branco, de que o Hemisfério Americano não era hostil à Europa.

Por isso, do fato de se reunir uma conferência americana, não se deve concluir que a América lance um desafio à Europa, e que o seu sentimento co-
A nossa reunião em Conferência incorre acaso na suspeita de ser uma liga internacional contra interêsse aqui não representađo... A própria vastidão 
Ietivo seja hostil ao progresso e ao ideal europeu. dos nossos territórios, em grande parte desertos, inexplorados alguns, e a certeza de que temos recursos para que neste continente viva na largueza uma população dez, vinte vêzes maior, nos aconselhartam a estreitar cada vez mais as relações de boa amizade, e a procurar desenvolver as de comércio com êsse inexaurivel viveiro de homens e fonte prodigiosa de energias fecundas que a Europa (4).

O artigo mostra também a constante preocupação de Rio Branco com a igualdade dos estados soberanos. Mais tarde, o Brasil apoiaria eloqüentemente esta idéia na Conferência de Paz de Haia.

o que a América deseja é a igualdade no direito internacional, que até aqui tem gozado, e que a soberania das suas nações seja acatada como a das nações européias.
Neles [congressos] se atende por igual ao direito do mais fraco como ao do mais poderoso (5).

$O$ terceiro exemplo da semelhança entre "O Congresso Pan-Americano" e os escritos de Rio Branco é a referência aos "princípios africanos", expressão que Rio Branco popularizou durante a sua campanha contra o Sindicato Boliviano, na disputa pelo Acre.

o que a América repele é tôda a tentativa de aplicaçāo dos chamados princípios africanos a qualquer porção -do seu continente livre.
Há monstruosidade em direito importanđo alienação parcial da soberania feita à sociedade estrangeira sem capacidade internacional. Há concessão para Áfica ou Ásia indigna do nosso continente (6).

O artigo refere-se ainda ao desêjo do Brasil de fortalecer a amizade que o unia aos Estados Unidos, tema êsse várias vêzes mencionado por Rio Branco durante aquêle período.

Não há amizade mais cobiçada no mundo. A Inglaterra proclama esta amizade como inquebrantável e, para não rompê-la, submeteu-se à mensagem nateres.
A verdade é que só havia grandes Potências da Europa e hoje elas são as primeiras a reconhecer que há no Novo Mundo uma grande e pode-

(4). - Rio Branco, discurso pronunctado aos 23 de julho de 1906, por ocasiáo da sessāo inaugural da Terceira Conferência Pan-Americana Obras do Barão do Rio Branco. IX Discursos (Rio, 1948), p. 87.

(5). - Ibid., p. 86 .

(6). - AHI, Rio Branco ao Ministro Brasileiro em Washington, 21 de janeiro de 1903, Telegramas Expedidos, 235-5-15. 
de Cleveland, considerada como ultimatum. rosa nação com que devem contar e que necessàriamente há de ter a sua: parté de influência na política internacional do mundo inteiro..., os mais poderosos governos da Europa... se ecmeram mais em dar públicas demonstrações de cordial amizade aos Estados. Unidos (7).

A quinta semelhança é a de idéias e expressões encontradas no artigo, que mais tarde apareceriam em "O Brasil, Os. Estados Unidos e o Monroísmo", escrito por Rio Branco sob. - pseudônimo de J. Penn, e que alcançou enorme publicidade. E' curioso verificar-se que apenas alguns meses separaram a publicação dêsses dois artigos.

Durante o Império, os três incidentes desagradáveis de Condy Raguet, no primeiro reinado, de Whise e Webb no segundo, foram resolvidos com honra para o Brasil, sem intervenção de qualquer outro pais, pelo Govêrno Americano, que desaprovou e puniu os seus agentes.
Refere-se o autor aos incidentes desagradáveis levantados por três representantes diplomáticos dos Estados Unidos no Brasil $\rightarrow$ Condy Raguet, em. 1827, Whise em 1846, e Webb, depois. de $1863 \ldots$ O Govêrno Americano... desaprovou o procedimento dos seus. agentes e os substituiu por outros (8).

Encontra-se uma evidência final na discussão sôbre a disputa pelo Amapá com a França, assunto intimamente ligado e familiar ao chanceler.

Para prova de quanto a simpatia dos Estados Unidos nos tem servido, basta referir que o arbitramento na questão do Oyapoc foi devido em grande parte à certeza havida em Paris de que o Brasil não estaria isolado no ca. so de uma nova tentativa de ocupação militar. Nessa época, tinham decorrido apenas alguns meses depois do altimatum Cleveland.
Penso também que o que contém: principalmente o Govêrno Francês é o. receio de complicação com os Estados umaos aa América e com a Inglaterra e talvez a desconfiança de que já tenhamos alguma inteligência secreta com os Governos dessas duas grandes Potências para a interposição dos seus bons ofícios no caso de ocupação militar do território contestado. A doutrina de Monroe, desenvolvida pelo Presidente Monroe, e os constantes embaraços que a Inglaterra procura sus-. citar na Africa e na Ásia à política. colonial seguida desde algum tempo. pela França devem ter feito refletir êste Govêrno (9).

(7). - AHI, Rio Branco à Legação Brastleira em Washington, 31 de janeiro de 1905, Despachos, 235-2-5.

(8). - J. Penn (Barão do Rio Branco), "ro Brasil, os Estados Unidos e o Monroismo", in Jornal do Comércio, 12 de maio de 1906, p. 2.

(9). - Palavras do Barão citadas por Delgado de Carvalho, História Diplomá... tica do Brasil (Rio, 1959), p. 206. 
Esses seis exemplos mostram claramente a semelhança entre $o$ artigo anônimo de um jornal e conhecidos escritos de Rio. Branco, semelhança esta por demais consistente para ser con-. siderada uma simples coincidência. Outras parcelas de evidência encontradas no artigo nos levam a crer na alegação de ter sido Rio Branco o seu autor. Quem quer que tenha escrito "O Congresso Pan-Americano", porém, conhecia de perto a história diplomática do Brasil e dos Estados Unidos, os acontecimentos da época na Alemanha, e as relações entre êste país e os. Estados Unidos. Eram relativamente poucos os brasileiros que possuiam um conhecimento especializado dêste conjunto específico de assuntos, além de Rio Branco, que já havia servido em postos diplomáticos tanto em Berlim como em Washington, e que era um reconhecido estudioso da História e da Diplomacia do Brasil. Além disso, o autor precisava necessàriamente ter recebido informações internas do Itamaratí para discorrer tão pormenorizadamente sôbre o Terceiro Congresso Pan-Ameicano e sôbre a vinda de Root e de Nabuco. O próprio Nabuco. confessou ter sido o artigo a primeira notícia vinda do Brasil a informar sua necessária participação na conferência (10). Tôdas as evidências circunstanciais baseadas no conteúdo do artigo indicavam que Rio Branco o escrevera.

O estadista brasileiro nunca perdeu seu entusiasmo vibran-. te pelo jornalismo. Quando era Ministro do Exterior, visitava freqüentemente a redação do Jornal do Comércio, que era conhecido como uma "espécie de porta-voz do chanceler" (11). Rio Branco gostava destas visitas noturnas ao jornal, onde êleescrevia ou ditava artigos, ou corrigia as provas dos parágrafos recém-escritos e importantes, que êle sentia merecerem uma. atenção especial (12). Dêsse modo, Rio Branco seguia uma prática estabelecida pela diplomacia européia, da qual era indubitàvelmente um conhecedor. Antes da Primeira Guerra Mundial, nas maiores capitais da Europa, os funcionários do govêrno costumavam muitas vêzes distribuir informações aos. jornais, informações que, por um motivo ou por outro, queriam ver divulgadas. Rio Branco fazia o mesmo no Jornal do

\footnotetext{
(10). - NA dos EUA, Nabuco a Root, 8 de janeiro de 1906, Notas da Legação. Brasileira, volume 8.

(11). - Luís Viaña Filho, A Vida do Barão do Rio Branco (Rlo, 1959), p. 392.

(12). - Levi Carneiro, Discnrsos e Conferências (Rio, 1954), p. 102; Afonso de Carvalho, Rio Branco (Rio, 1945), p. 209; Vlana Filho, A Vlda, p. 373 e: p. 382; Alvaro Lins, Rio Branco, II, p. 642.
} 
Comércio, cujo editor, certa vez, citou o Ministro do Exterior como sendo "o melhor repórter do Jornal do Comércio" (13). Referindo-se às suas próprias contribuições àquêle respeitável matutino, Rio Branco escreveu ao editor José Maria Rodrigues:

"O Jornal do Comércio... fôlha em que eu trabalho como V. sabe (ainda ontem à noite mandei-lhe matéria para quase uma coluna)... o amigo que perde noites inteiras a defender os interêsses da paz neste país e também a trabalhar para que o Jornal se mostre sempre bem informado" (14).

Outras cartas trocadas entre os dois homens demonstram a participação ativa de Rio Branco nas colunas daquele jornal (15) . O Jornal do Comércio, orgulhando-se de longa data da colaboração prestada pelo eminente estadista, publicou, em 1957, um histórico das relações entre o jornal e Rio Branco (16).

Dêsse modo, a atribuição da autoria do artigo a Rio Branco baseia-se, em primeiro lugar, nas declarações de Nabuco referentes ao artigo, favorecendo tal conclusão; em segundo, no estilo, na escôlha de palavras-chave, no conjunto dos tópicos e no conhecimento revelados, indicando que Rio Branco foi, provàvelmente, a única pesosa capaz de escrevê-lo; finalmente, no fato do Barão do Rio Branco ter o costume de escrever para o Jornal do Comércio, quer por pseudônimo, quer anônimamente. Os redatores do jornal provàvelmente acrescentaram o parágrafo final, um tributo ao estadista, mas a essência do artigo trouxe a público o cunho inconfundível do grande chanceler e expressou os "pontos de vista do Ministro do Exterior" (17), para usar das próprias palavras de Nabuco. Na verdade, Rio Branco não remeteria o artigo a Nabuco se êle não transmitisse as opiniões do Itamaratí.

Por ser um dos raros pronunciamentos sôbre política externa escritos por Rio Branco, o artigo reveste-se de enorme importância. Contém uma afirmação do Ministro do Exterior

(13). - Trixeira Soares, O Barão do Rio Branco e a Diplomacia Brasileira (Pôrto Ale $_{t}$ Te, 1946), p. 21.

(14). - Rio Branco a J. IM. Rodrígues, 21 de agôsto de 1908. Citada por Viana Filho, A Vida, p. 401.

(15). - Biblioteca Nacional, Secção de Manuscritos, Cartas de Rio Branco a J. C. Rodrígues, I.3.4.46, I.3.4.59, e I.3.4.60.

(16). - "O Barão do Rio Branco e o "Jornal do Comércto" ", in Jornal do Comércio, 21 de fevereiro de 1957, p. 2 .

(17) : - NA dos EUA, Nabuco a Root, 8 de janeiro de 1906, Notas da Legação Brasileira, volume 8 . 
de que a política externa do Brasil era uma expressão externa de suas condições internas. Parte das palavras do texto são:

"A brilhante política internacional, em que resolutamente entrou o Brasil, será um fator de progresso interno".

A expressão do bem-estar interno do Brasil numa política externa bem sucedida, raramente melhor ilustrada do que na época de Rio Branco, tornou-se uma verdade evidente da História do Brasil, tanto quanto uma idéia tradicional no pensamento do Itamaratí. Fernando Ramos de Alencar, no início de 1960, escreveu:

"Existe... uma ligação intima entre a ação nacional e a ação internacional, entre a política doméstica e a política externa, sendo ambas duas partes distintas do mesmo pensamento fundamental e da mesma finalidade" (18) .

Mais recentemente, Afonso Arinos de Melo Franco, de maneira mais concisa, assim se expressou:

"A política externa é uma projeção de nossa personalidade nacional que se prolonga na esfera internacional" (19).

Rio Branco compreendia perfeitamente esta relação, e sua política externa revelou estar êle consciente desta atuação recíproca. "O Congresso Pan-Americano" foi seu reconhecimento escrito dêste princípio.

Rio Branco esboçou no artigo objetivos de sua política externa. Primeiramente, havia uma preocupação com o principio da "igualdade no direito internacional" e de "que a soberania de suas nações [da América] seja acatada como a das nações européias". Devido às crenças de Rio Branco, o Brasil foi a primeira grande nação a trabalhar em favor da igualdade das nações soberanas. Rio Branco, através de seu embaixador Rui Brbosa, aumentou agressivamente essa idéia em Haia, em 1907. O Brasil estava avançado para sua época. Sòmente várias décadas mais tarde, iria o mundo aceitar o princípio de igualdade de tôdas as nações, uma parte da política internacional já adotada por Rio Branco em 1905.

\footnotetext{
(18). - "Some Postulates of Brazilian Foreign Policy", Brazilian-American Survey, n.o 12 (1960), p. 6.

(19). - Brazll Herald, Rio de Janeiro, 24 de julho de 1962, p. 2
} 
Em segundo lugar, Rio Branco reafirmava a aceitação da Doutrina de Monroe pelo Brasil. Em 1824, o Brasil fôra a primeira nação a aprovar aquela doutrina norte-americana. Com pequenas exceções, o Brasil a apoiaria daí por diante. A 2 de dezembro de 1904, o Presidente Theodore Roosevelt alargou a Doutrina, a fim de fornecer à ação político-internacional dos Estados Unidos meios que impedissem uma intervenção européia no Hemisfério Oriental. Rio Branco imediatamente aplaudiu e secundou o nôvo corolário, referindo-se elogiosamente à Doutrina de Monroe:

"O Brasil, que é solidário com esta interpretação de monroismo, orgulha-se com a simpatia espontânea e decidida da nação americana e do seu grande Presidente".

- Em terceiro lugar, o artigo não deixava margem a dúvidas sôbre o fato de que um dos objetivos da política externa do Brasil era o de fortalecer "a franca e estreita amizade" com os Estados Unidos, usando as palavras de um despacho diplomático brasileiro da época (20). O tom empregado em todo o artigo era extremamente favorável e cordial aos Estados Unidos. Neste ponto, o artigo exprimia a política de amizade com os Estados Unidos, estabelecida de longa data por Rio Branco. Com aproximadamente um mês de exercício do seu mandato, o referido estadista informou ao Ministro brasileiro nos Estados Unidos que desejava que o Brasil

\section{"estivesse sempre de acôrdo com o govêrno de Was- hington" (21).}

Em "O Congresso Pan-Americano", Rio Branco mencionou várias vantagens que o Brasil poderia obter desta ligação íntima com os Estados Unidos, além de razões políticas, comerciais e históricas que justificavam tal amizade. De acôrdo com o artigo, "maior aproximação" entre as duas nações foi uma das principais realizações de Rio Branco.

Um quarto objetivo de sua política externa foi o de assegurar para o Brasil “ um lugar preeminente entre as nações americanas". Rio Branco acreditava firmemente em suas palavras ao dizer: "o respeito e a simpatia que nos chegam das

(20). - AHI, Gomes Ferreira a Rio Branco, 5 de maio de 1905, Washington, Oficlo 234-1-3.

(21). - AHI, Rio Branco ao Ministro Brasileiro em Washington, 5 de janeiro de 1903, Telegramas Expedidos, 235-3-15. 
outras nações aumentarão a nossa responsabilidade e nos darão maior consciência do nosso destino". O patriotismo e a devoção a seu país, que sempre caracterizaram Rio Branco, levaram-no a continuar uma política externa de engrandecimento nacional.

Esse artigo esquecido de um jornal de 1905 delineou quatro objetivos da política externa do Brasil, quando sob a liderança dinâmica de Rio Branco: a igualdade das nações, a aceitação do nôvo corolário da Doutrina de Monroe, uma amizade mais estreita com os Estados Unidos e'o engrandecimento do Brasil. Êstes não são, de forma alguma, os únicos objetivos da política externa de Rio Branco. Formam, entretanto, uma parte integral de seu programa global.

O artigo é de capital importância para o estudo do ministério de Rio Branco, por ser um de seus raros pronunciamentos escritos sôbre sua política externa, cujos objetivos, como demonstra a História, foram alcançados através de uma diplomacia bem sucedida.

\section{E. BRADFORD BURNS}

University of New York at Buffalo. 